\title{
Optimización estadística de un bioproceso de ácido láctico a partir de lactosuero
}

\author{
Jessica M. Flores Tixicuro \\ jmflorest@utn.edu.ec \\ José Manuel País Chanfrau \\ jmpais@utn.edu.ec \\ Ima S. Sánchez de Céspedes \\ issanchez@utn.edu.ec \\ Marcos V. Lara Fiallos \\ mvlara@utn.edu.ec \\ Jimmy Núñez Pérez \\ jnunez@utn.edu.ec \\ Facultad de Ingeniería en Ciencias Agropecuarias y Ambientales (FICAYA), Universidad \\ Técnica del Norte (UTN), \\ Ave. 17 de julio, 5-21, y Ave. Gral. José M. de Córdova, \\ CP 100105, Ibarra - Ecuador
}

\section{RESUMEN}

El uso de residuales de la industria como sustrato es tendencia a nivel mundial, el lactosuero es uno de ellos. El objetivo de la investigación fue encontrar la combinación de temperatura y $\mathrm{pH}$ que maximicen la productividad de ácido láctico con el uso de lactosuero y Lactobacillus casei. Se evaluaron las variables de temperatura en los valores de $\left(29,31.1,37,42.7\right.$ y $\left.45{ }^{\circ} \mathrm{C}\right)$ y $\mathrm{pH}(4.8,5,5.5,6$ y 6.2) para encontrar parámetros óptimos del bioproceso que maximicen la productividad volumétrica de ácido láctico mediante el uso del Diseño Central Compuesto utilizando el programa Design Expert 11.0. Se realizaron trece corridas. Se verificó la validez del modelo cuadrático mediante 3 repeticiones con los parámetros óptimos sugeridos por el programa y se determinó que las condiciones de maximización de la productividad volumétrica son $40.2{ }^{\circ} \mathrm{C}$ de temperatura y $5.6 \mathrm{de} \mathrm{pH}$, alcanzando valores de $1.2 \mathrm{gl}^{-1} \mathrm{~h}^{-1} \mathrm{y}$ se confirmó que no existe diferencia significativa $(\mathrm{p} \leq 0.05)$ con los valores brindados por el modelo. Concluyendo que los valores óptimos de temperatura y $\mathrm{pH}$ encontrados fueron cercanos a los reportados por otros autores y se demostró que el lactosuero tiene un gran potencial para ser utilizado como sustrato.

Palabras clave: lactosuero; bioproceso; L. casei; diseño central compuesto; optimización. 


\title{
Statistical optimization of a lactic acid bioprocess from whey
}

\begin{abstract}
The use of industrial waste as a substrate is a worldwide trend, whey is one of them. The objective of the research was to find the combination of temperature and $\mathrm{pH}$ that maximizes the productivity of lactic acid with the use of whey and Lactobacillus casei. The temperature variables were evaluated in the values of $\left(29,31.1,37,42.7\right.$ and $\left.45^{\circ} \mathrm{C}\right)$ and $\mathrm{pH}(4.8,5,5.5,6$ and 6.2) to find optimal parameters of the bioprocess that maximize the volumetric productivity of lactic acid. by using the Central Composite Design using the Design Expert 11.0 program. Thirteen runs were carried out. The validity of the quadratic model was verified through 3 repetitions with the optimal parameters suggested by the program, and it was determined that the conditions for maximizing volumetric productivity are $40.2{ }^{\circ} \mathrm{C}$ of temperature and $5.6 \mathrm{of} \mathrm{pH}$, reaching values of $1.2 \mathrm{~g} . \mathrm{l}^{-1} \mathrm{~h}^{-1}$ and it was confirmed that there is no significant difference $(\mathrm{p} \leq$ 0.05) with the values provided by the model. Concluding that the optimal values of temperature and $\mathrm{pH}$ found were close to those reported by other authors and it was shown that whey has great potential to be used as a substrate.
\end{abstract}

Keywords: whey; bioprocess; L. casei; composite core design; optimization.

Artículo recibido: 05 de Mayo 2021 Aceptado para publicación: 20 de Junio 2021

Correspondencia: jnunez@utn.edu.ec Conflictos de Interés: Ninguna que declarar 


\section{INTRODUCCIÓN}

El ácido láctico es un ácido carboxílico (ácido orgánico) por poseer un grupo funcional carboxilo (-COOH). Este compuesto químico tiene importantes roles en los procesos bioquímicos y por su versatilidad es utilizado en la industria como preservante, acidulante, saborizante, como materia prima para la producción de biopolímeros, éster de lactato, ácido propanoico, ácido acrílico (Helmes et al., 2018).

En las últimas cinco décadas se ha estimado un crecimiento a nivel mundial de la producción del ácido láctico anual de un poco más del 15\%, para el año 2020 se ha considerado que llegaría a 1,960 kilotoneladas (The observatory of economic complexity [OCE], 2017). Los consumos a nivel mundial por sectores serían: en la obtención de polímeros 39\%, alimentos y bebidas 35\%, productos de aseo el 13\%, en solventes y otros usos industriales 13\% (Komesu et al., 2017). Este ácido ha desempeñado un papel transcendental para detener la transmisión del virus COVID-19 entre personas, donde se emplea como sustancia activa, en productos antisépticos y desinfectantes químicos, usados en la desinfección de superficies, áreas y uso ambiental (Dirección General de Salud Pública [DGSP], 2020, p 36-40).

El ácido láctico se encuentra en su forma natural en plantas y animales. Industrialmente, se puede obtener por un bioproceso a partir de fermentación de carbohidratos (Sauer et al., 2017; Teusink y Molenaar, 2017) o también por síntesis química a partir de los derivados del petróleo (Juodeikiene et al., 2015).

En los últimos años la obtención de ácido láctico por vía biotecnológica ha sido la más empleada ya que, permite obtener de forma más pura tanto el isómero (L), como (D) (Teusink \& Molenaar, 2017; Abdel-Rahman et al., 2019). Por esta vía en la mayoría de los casos los medios de cultivos empleados son suplementados e inoculados con un microorganismo seleccionado para dar lugar al proceso de fermentación (Ghaffar et al., 2014; Guillamón \& Mas, 2017). Para lograr un proceso exitoso es necesario establecer las condiciones durante la fermentación que favorecen tanto el crecimiento celular como la producción del metabolito, estos pueden ser: el pH, temperatura, agitación y sus valores van a depender del tipo de microorganismo seleccionado (Kuo et al., 2015). La fermentación puede alcanzar altos rendimientos y se puede dirigir la selectividad de los isómeros por separados, así como su mezcla racémica (Eiteman \& Ramalingam, 2015). 
La búsqueda de sustratos económicos y nuevas tecnologías de fermentación es de gran interés por parte de los productores, ya que promueven el desarrollo y la competitividad de los procesos (Eş et al., 2018). La tendencia actual se basa en el uso de residuos agroindustriales que aún poseen concentraciones importantes de carbohidratos o polisacáridos que pueden ser hidrolizados. Algunas de las tendencias en ascenso del uso de residuos son, el suero de leche, la pulpa, el mucílago de café y cacao, melaza de caña de azúcar, entre otros (Gopinath et al., 2016; Reddy et al., 2016).

Dentro de los microorganismos utilizados para la producción de ácido láctico se encuentran las bacterias y los hongos, estos últimos presentan algunas ventajas, ya que tienen la capacidad de producir y secretar amilasas que hidrolizan almidón, evitando de esta forma un paso adicional de hidrólisis (Londoño-Hernández et al., 2017). En el caso de la bacterias ácido-lácticas (BAL), son las que poseen la capacidad de producir ácido láctico como el principal producto de la fermentación, la mayoría son catalasas negativas (Gorbeña \& Sáenz, 2008), no forman micelios y pueden llegar a soportar temperaturas máximas de $45^{\circ} \mathrm{C}$, estas $\mathrm{BAL}$ tienen mayor tolerancia a $\mathrm{pH} \leq 5$ que el resto de las bacterias, lo que les proporciona ventajas para la producción de ácidos orgánicos. Son reconocidas como prebióticos, probióticos y capacidad antimicrobiana (Vanegas et al., 2017; García Gonzalez et al., 2017).

El más diverso del género de BAL son los Lactobacillus, que incluye especies con diferentes propiedades fisiológicas y bioquímicas (Chapot-Chartier \& Kulakauskas, 2014), las cuales las hace muy especial al resistir en un ambiente ácido y debido a esta cualidad, se logra obtener altas productividades de ácido láctico y biomasa, siendo los más utilizados en los procesos industriales (Taskila \& Ojamo, 2013). Estas BAL poseen dos rutas para fermentar la glucosa y se dividen en dos grupos: homofermentativos (produce solo ácido láctico) y heterofermentativos obligatorios (produce ácido láctico y otros) (Teusink \& Molenaar, 2017).

Teniendo en cuenta lo antes expuesto el objetivo de esta investigación fue encontrar la combinación de temperatura y $\mathrm{pH}$ que maximicen la productividad de ácido láctico con el uso de un sustrato económico como el lactosuero y Lactobacillus casei. 
<smiles>CC(O)C(=O)O</smiles>

Lactic acid

Nombre IUPAC:

Ácido 2-hidroxipropanoico

Formula Molecular: $\mathrm{C}_{3} \mathrm{H}_{6} \mathrm{O}_{3}$

MM: $90.078 \mathrm{~g} \cdot \mathrm{mol}^{-1}$

Acidez: $3.86 \mathrm{p} K_{a}$

\section{MATERIALES Y MÉTODOS}

El microorganismo utilizado fue Lactobacillus casei-01. Los resultados fueron obtenidos en los laboratorios de la Carrera Agroindustrial en la Universidad Técnica del Norte, Ibarra, Ecuador. El bioproceso se realizó siguiendo los pasos detallados en la Figura 1.



Figura 1. Diagrama del bioproceso para la producción de ácido láctico

Conducción el experimento: el proceso de fermentación comienza a partir de un vial que forma parte de un banco de células de trabajo (BCT) obtenido a partir de la activación una cepa liofilizada de L casei -01, llevado a cabo según la metodología (Panesar et al., 2010). 
El proceso se llevó a cabo en el fermentador de vidrio con capacidad total de $4 \mathrm{~L}$, el cual está debidamente equipado (control de temperatura, $\mathrm{pH}$ y motor para agitación con impelente turbina Rushton) el modo de operación aplicado fue por lote.

En todas las corridas se inició con la misma concentración celular a partir de $50 \mathrm{ml}$ de cultivo previamente activado por $24 \mathrm{~h}$ a $37^{\circ} \mathrm{C}$ de un vial del BCT en 2 litros de sustrato (lactosuero) bajo condiciones anaerobias. Se inició el bioproceso a pH 6.5 dejando caída libre de este hasta alcanzar el valor fijado en el control, se utilizó $\mathrm{Ca}(\mathrm{OH})_{2}$ al $2.5 \mathrm{~N}$ como agente neutralizante. Se definió como final del proceso una vez alcanzada la fase estacionaria. Las ecuaciones químicas que tienen lugar en el bioproceso son las siguientes:

\section{a) Fermentación y neutralización}

$$
2\left(\mathrm{C}_{3} \mathrm{H}_{6} \mathrm{O}_{3}\right)+\mathrm{Ca}(\mathrm{OH})_{2} \quad \rightarrow \quad \mathrm{Ca}\left(\mathrm{CH}_{3} \mathrm{CHOHCOO}\right)_{2}+2 \mathrm{H}_{2} \mathrm{O}
$$

b) Hidrólisis por $\mathrm{H}_{2} \mathrm{SO}_{4}$

$$
\mathrm{Ca}\left(\mathrm{CH}_{3} \mathrm{CHOHCOO}\right)_{2} \quad+\mathrm{H}_{2} \mathrm{SO}_{4} \rightarrow 2\left(\mathrm{CH}_{3} \mathrm{CHOHCOOH}\right)+\mathrm{CaSO}_{4}
$$

Para la recuperación de la molécula de ácido láctico (ec. 2) se añadió ácido sulfúrico al 2,5 $\mathrm{N}$ que reacciona con el lactato de calcio, formando sulfato de calcio y ácido láctico. Obteniendo que $1 \mathrm{~mol}$ de $\mathrm{Ca}(\mathrm{OH})_{2}$ equivale a $2 \mathrm{~mol}$ ácido láctico formado.

Las mediciones de la concentración de ácido láctico durante cada corrida se realizaron por el método de titulación (Fabro et al., 2006).

Análisis estadístico: Se optó por el uso de un paquete estadístico, Design Expert 11.0, empleando el Método de superficie de respuesta (RSM) con Diseño Central Compuesto aplicado para la optimización, los factores en estudio fueron A (temperatura ${ }^{\circ} \mathrm{C}$ ) y factor




B (pH) Figura 2.

Figura 2. Superficie explorada en la investigación.

La optimización de las condiciones de fermentación se realizó por combinaciones de los niveles de los dos factores independientes: temperatura de incubación $\left(29-45^{\circ} \mathrm{C}\right)$ y $\mathrm{pH}$ (4.8-6.2) con un total de 13 tratamientos para la maximización de la productividad volumétrica del ácido láctico $\left(\mathrm{g} . \mathrm{l}^{-1} \mathrm{~h}^{-1}\right)$.

La correlación entre las variables independientes y la variable dependiente fueron expresadas en función de un modelo estadístico cuadrático:

$\mathrm{P}=\beta_{0}+\beta_{1} \mathrm{X}_{1}+\beta_{2} \mathrm{X}_{2}+\beta_{1 * 2} \mathrm{X}_{1} \mathrm{X}_{2}+\beta_{1}{ }^{2} \mathrm{X}_{1}^{2}+\beta_{2}{ }^{2} \mathrm{X}_{2}^{2}+\varepsilon$

\section{Donde:}

P: productividad volumétrica de ácido láctico $\left(\mathrm{g} . \mathrm{l}^{-1} \mathrm{~h}^{-1}\right)$

$\mathbf{X}_{\mathbf{1}}$ : Factor A (Temperatura ${ }^{\circ} \mathrm{C}$ )

$\mathbf{X}_{2}$ : Factor B $(\mathrm{pH})$

$\beta_{0}$ : es el coeficiente constante

$\beta_{1}$ : representa el efecto del factor $\mathrm{X}_{1}$ (Temperatura de incubación)

$\beta_{2}$ : representa el efecto del factor $\mathrm{X}_{2}(\mathrm{pH})$

$\boldsymbol{\beta}_{1} *_{2}$ : representa el efecto de las interacciones entre los factores $\mathrm{X}_{1}$ y $\mathrm{X}_{2}$

$\beta_{1^{2}}$ : representa el efecto cuadrático del factor $X_{1}$

$\boldsymbol{\beta}_{2}^{2}$ : representa el efecto cuadrático del factor $\mathrm{X}_{2}$

$\varepsilon$ : componente del error aleatorio del modelo

\section{RESULTADOS Y DISCUSIÓN}

Pre-inóculo: Las bacterias ácido-lácticas (L. casei-01) liofilizadas fueron activadas, mediante el cultivo en caldo y agar MRS (Figura 3).
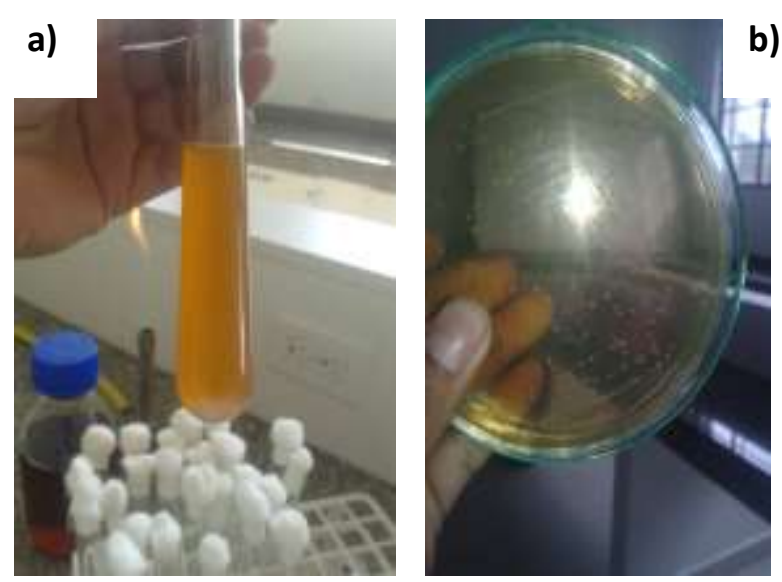
Figura 3. Activación del microorganismo. a) cultivo de $0.1 \mathrm{~g}$ de L. casei en $10 \mathrm{ml}$ de caldo MRS por 24 h a $37{ }^{\circ} \mathrm{C}$; b) cultivo en medio sólido, se incubó a $37{ }^{\circ} \mathrm{C}$ por $48 \mathrm{~h}$.

Se demostró la viabilidad y especificidad de la cepa, teniendo una media de crecimiento de $2.63 \times 10^{8} \mathrm{UFC} / \mathrm{ml}$. Se procedió a la elaboración del banco de células de trabajo donde se obtuvieron 25 viales con una concentración de biomasa del $1.71 \%(\mathrm{~m} / \mathrm{v})$ se almacenaron a $-18{ }^{\circ} \mathrm{C}$. Esto garantizó que todos los procesos iniciaron con la misma concentración celular, garantizando que los cultivos permanezcan puros y homogéneos bajo condiciones que aseguren la estabilidad microscópica, macroscópica, bioquímica, fisiológica y genética (Parra Huertas et al., 2006).

Para el análisis de las variables estudiadas de temperatura y pH se tomó el valor más alto de productividad volumétrica de ácido láctico una vez alcanzada la fase estacionaria, los datos se reportan en la Tabla 1.

Tabla 1. Resultados obtenidos del bioproceso.

\begin{tabular}{cccccc}
\hline $\mathrm{T}$ & $\begin{array}{c}\text { Temperatura } \\
\left({ }^{\circ} \mathrm{C}\right)\end{array}$ & $\mathrm{pH}$ & $\begin{array}{c}\text { Concentración } \\
\text { de } \mathrm{AL}(\mathrm{g} / \mathrm{l})\end{array}$ & $\begin{array}{c}\text { Tiempo } \\
(\mathrm{h})\end{array}$ & $\begin{array}{c}\text { Productividad volumétrica } \\
\text { de AL }\left(\mathrm{g} . \mathrm{l}^{-1} \mathrm{~h}^{-1}\right)\end{array}$ \\
\hline 1 & 37.0 & 5.5 & 18.90 & 15.0 & 1.26 \\
2 & 37.0 & 5.5 & 18.79 & 17.0 & 1.11 \\
3 & 31.3 & 6.0 & 16.88 & 33.0 & 0.51 \\
4 & 37.0 & 5.5 & 18.51 & 16.0 & 1.16 \\
5 & 37.0 & 5.5 & 15.02 & 15.0 & 1.26 \\
6 & 37.0 & 5.5 & 18.34 & 15.0 & 1.22 \\
7 & 29.0 & 5.5 & 32.06 & 40.0 & 0.8 \\
8 & 42.7 & 5.0 & 23.63 & 25.0 & 0.95 \\
9 & 37.0 & 4.8 & 16.88 & 27.5 & 0.61 \\
10 & 45.0 & 5.5 & 16.31 & 17.0 & 0.96 \\
11 & 37.0 & 6.2 & 23.91 & 25.0 & 0.96 \\
12 & 31.3 & 5.0 & 15.75 & 50.0 & 0.32 \\
13 & 42.7 & 6.0 & 37.01 & 30.0 & 1.23 \\
\hline
\end{tabular}

*ácido láctico $(\mathrm{AL})$

Mediante los valores reales encontrados de la variable de respuesta Tabla 1 se ajustó y se validó debidamente el modelo, luego se procedió a explorar en la superficie descrita por el programa para encontrar la combinación óptima de niveles de los factores independientes que den como respuesta el punto óptimo para hallar la máxima productividad volumétrica. El cual proporcionó los datos del modelo, ANOVA y 
posibles combinaciones de variables independientes que cumplen con condiciones que optimice la productividad volumétrica del ácido láctico (Figura 4).

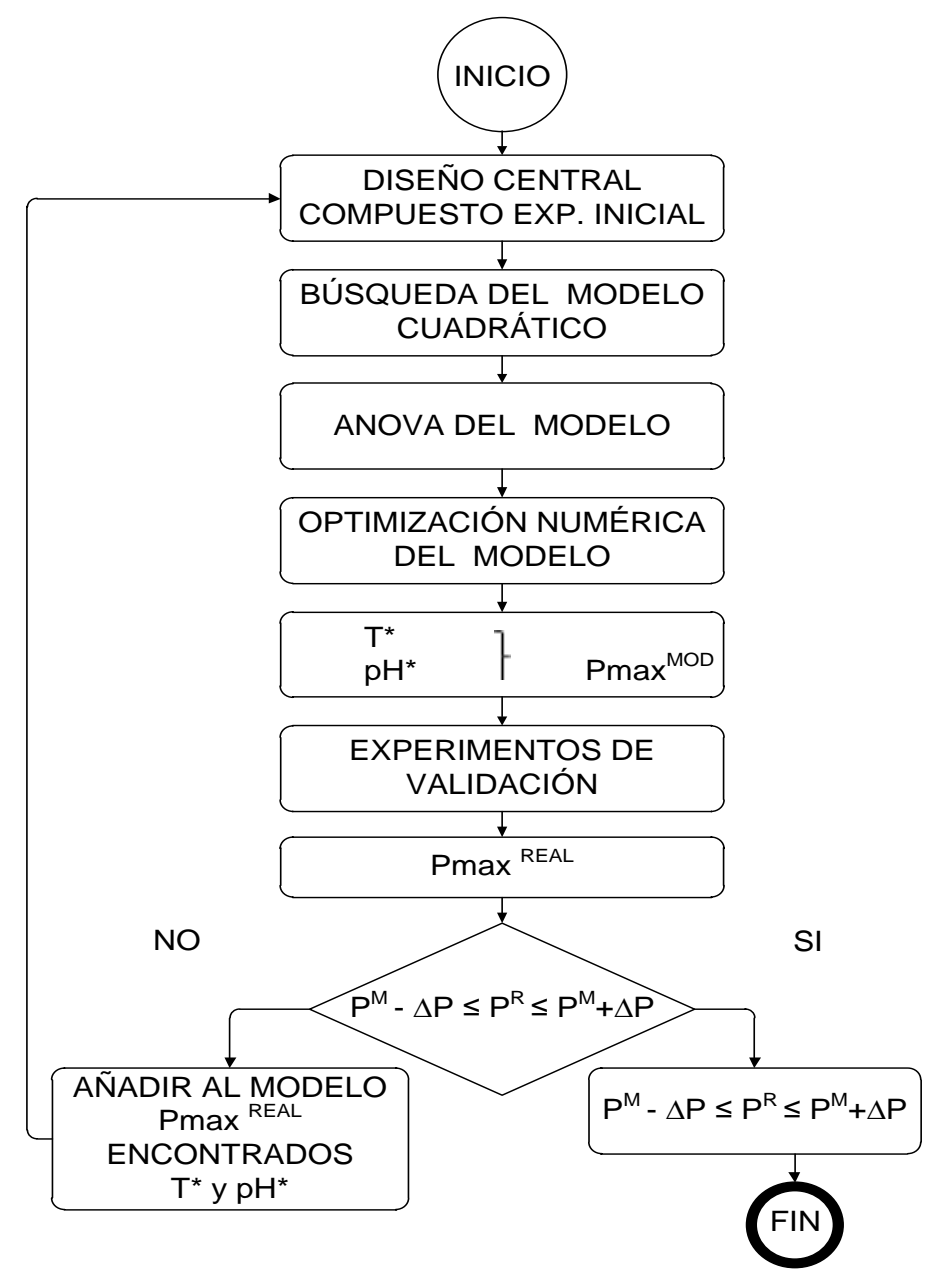

Figura 4. Diagrama para la obtención del punto óptimo.

Los valores obtenidos de la variable dependiente se ajustaron a un modelo cuadrático para la productividad volumétrica de ácido láctico. El modelo de la variable de respuesta expresada en factores reales en la ec. 3 .

$\mathrm{P}=-35,75+0,41 * \mathrm{~T}+10,21^{*} \mathrm{pH}+0,008 \mathrm{~T}^{*} \mathrm{pH}-0,0056^{*} \mathrm{~T}^{2}-0,93 * \mathrm{pH}^{2}$

\section{Donde:}

P: productividad volumétrica del ácido láctico $\left(\right.$ g. $\left.\mathrm{l}^{-1} \mathrm{~h}^{-1}\right)$; T: temperatura $\left({ }^{\circ} \mathrm{C}\right)$.

La ec. 3 puede ser usada para hacer predicciones de la variable de respuesta, dados los niveles de cada factor.

En la Tabla 2 se muestra el análisis de varianza (ANOVA) del modelo sugerido y el análisis estadístico, el cual permitió conocer si el modelo estadístico sugerido es útil para determinar el punto óptimo de la productividad volumétrica de ácido láctico. 
Tabla 2. Análisis de varianza del modelo cuadrático

\begin{tabular}{lcccccc}
\hline FV & SC & GL & CM & Valor F & Valor p & $\begin{array}{l}\text { Significanci } \\
\text { a }\end{array}$ \\
\hline Modelo & 0.954 & 5 & 0.1908 & 7.1 & 0.0114 & $* * *$ \\
A- Temperatura & 0.3106 & 1 & 0.3106 & 11.56 & 0.0114 & $* * *$ \\
B-pH & 0.1164 & 1 & 0.1164 & 4.33 & 0.0759 & ns \\
$\mathrm{A}^{2}$ & 0.2279 & 1 & 0.2279 & 8.49 & 0.0226 & $* * *$ \\
$\mathrm{~B}^{2}$ & 0.3632 & 1 & 0.3632 & 13.52 & 0.0079 & $* * *$ \\
Residuo & 0.188 & 7 & 0.0269 & & & $* * *$ \\
Falta de ajuste & 0.1707 & 3 & 0.0569 & 13.17 & 0.0153 & $*$ \\
Error puro & 0.0173 & 4 & 0.0043 & & & \\
Total & 1.14 & 12 & & & & \\
\hline
\end{tabular}

Nota: $(* * *)$ alta significancia; (ns) no existe significancia.

En el análisis del ANOVA muestra que el valor p del modelo es < a 0.05 lo indica que es significativo, el término del efecto lineal de temperatura (A), el término del efecto cuadrático de la temperatura $\left(\mathrm{A}^{2}\right)$ y $\mathrm{pH}\left(\mathrm{B}^{2}\right)$ también son significativos. Valores mayores a 0.1 indican que los términos del modelo no son significantes en este caso el $\mathrm{pH}$ (B). El coeficiente de determinación ajustado $\mathrm{R}^{2}$ ajustado fue de 0.7178 lo que indica que el modelo utilizado en la búsqueda de la máxima productividad volumétrica del ácido láctico es satisfactorio, si el modelo no muestra un mínimo de 0.70 del comportamiento de la respuesta en término de $\mathrm{R}^{2}$ ajustado, no se recomienda utilizar con fines de optimización ya que su predicción no sería adecuada (Gutiérres Pulido \& De la Vara Salazar, 2008).

Luego de haber realizado el análisis de Varianza (ANOVA) del modelo, el programa sugirió más de una combinación dentro de los niveles de los factores en estudio que cumplen con las condiciones de optimización (Tabla 3).

Tabla 3. Condiciones óptimas sugeridas para la productividad volumétrica de ácido láctico.

\begin{tabular}{ccc}
\hline Condición & A: Temperatura $\left({ }^{\circ} \mathrm{C}\right)$ & B: $\mathrm{pH}$ \\
\hline 1 & 38.7 & 5.6 \\
2 & 40.2 & 5.6 \\
3 & 41.2 & 5.7 \\
\hline
\end{tabular}


Se escogió una combinación con el fin de realizar la validación del modelo y los resultados de la variable de respuesta confirman el valor de la productividad predicha, ya que el valor real obtenido cae dentro de los rangos $\left(1.10-1.40\right.$ g. $\left.\mathrm{l}^{-1} \mathrm{~h}^{-1}\right)$ que el programa señala como óptimos (Tabla 4).

Tabla 4. Puntos predichos de productividad máxima para el 95\% de Confianza.

\begin{tabular}{lccc}
\hline Variable de respuesta & Observada & Baja & Alta \\
\hline Productividad volumétrica $\left(\mathrm{g} . ~^{-1} \mathrm{~h}^{-1}\right)$ & 1.27 & 1.10 & 1.40 \\
\hline
\end{tabular}

Los valores óptimos de temperatura de $40.2{ }^{\circ} \mathrm{C}$ y $\mathrm{pH}$ de 5.6 obtenidos en este estudio confirman lo reflejado en otros estudios (Singh et al., 2006; Trontel et al., 2010), quienes describen que las condiciones óptimas de producción de ácido láctico varían según las cepas de bacterias utilizadas, pero de forma general los valores de $\mathrm{pH}$ varían entre 5-7 y la temperatura de fermentación varían de 40 a $45^{\circ} \mathrm{C}$.

El programa estadístico proporcionó representaciones gráficas de los puntos óptimos, de temperatura y $\mathrm{pH}$ (Figura 5).
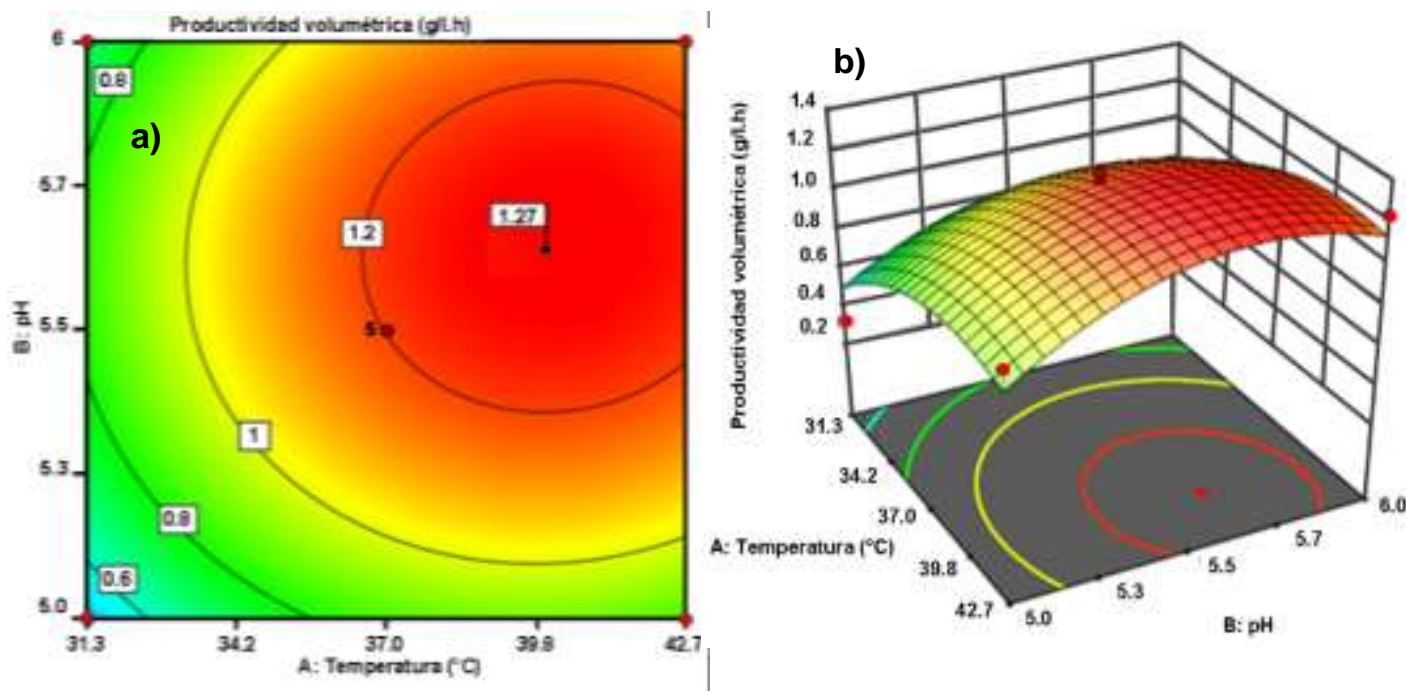

Figura 5. Representación del punto óptimo de la productividad a) 2D y b) 3D.

La zona roja representa los puntos óptimos de temperatura y $\mathrm{pH}$ que maximizan la productividad volumétrica del ácido láctico, se puede asegurar que cualquier punto dentro de esta zona el resultado de productividad volumétrica será el máximo. 
En la Tabla 5 se presentan productividades volumétricas de ácido láctico utilizando diferentes especies de L. casei, condiciones de sustrato, suplementos y condiciones de fermentación:

Tabla 5. Comparación de Productividad volumétrica de ácido láctico en cultivos por lotes.

\begin{tabular}{|c|c|c|c|c|c|}
\hline Sustrato & Microorganismo & Suplemento & Condición & $\begin{array}{c}\text { Productividad } \\
\text { volumétrica } \\
\left(\text { g. } \mathbf{l}^{-1} \mathbf{h}^{-1}\right)\end{array}$ & Fuente \\
\hline MRS & $\begin{array}{l}\text { Lactobacillus } \\
\text { amylovorus DSM } \\
20531 \mathrm{~T}\end{array}$ & Almidón 10 g. $1^{-1}$ & $\begin{array}{c}\mathrm{pH} 5.5 ; 45 \\
{ }^{\circ} \mathrm{C}\end{array}$ & 1.45 & $\begin{array}{l}\text { (Trontel et } \\
\text { al., 2010) }\end{array}$ \\
\hline Lactosuero & L. casei- 01 & -- & $\begin{array}{l}\text { pH 5.6; } \\
40.2^{\circ} \mathrm{C}\end{array}$ & 1.27 & $\begin{array}{c}\text { Este } \\
\text { estudio }\end{array}$ \\
\hline Lactosa & L. casei ATCC & Sulfato de amonio & $37^{\circ} \mathrm{C} ; \mathrm{pH}$ & 1.10 & (Arrázola \\
\hline 87.4 g. $1^{-1}$ & 393 & 5 g. $\mathrm{l}^{-1}$ & inicial 6.5 & & $\begin{array}{c}\text { Paternina et } \\
\text { al., 2013) }\end{array}$ \\
\hline $\begin{array}{l}\text { Lactosuero } \\
50 \mathrm{~g} \cdot \mathrm{l}^{-1}\end{array}$ & $\begin{array}{l}\text { L. casei subsp. } \\
\text { casei ATCC } 39392\end{array}$ & $\begin{array}{c}\text { LMF; Glucosa: } 80 \\
\text { g. } 1^{-1}\end{array}$ & $\begin{array}{l}\mathrm{pH} 4.8-5 ; \\
42^{\circ} \mathrm{C} ; \mathrm{CI}\end{array}$ & 0.63 & $\begin{array}{l}\text { (Mirdamadi } \\
\text { et al., 2008) }\end{array}$ \\
\hline
\end{tabular}

*Extracto de levadura (E.L); Licor de maíz fermentado (LMF); Células inmovilizadas (CI); medio de cultivo selectivo Man, Rogosa y Sharpe (MRS).

El valor máximo alcanzado en esta investigación de la productividad volumétrica de ácido láctico fue de $1.27 \mathrm{~g} . \mathrm{l}^{-1} \mathrm{~h}^{-1}$, aunque en otros estudios se alcanzaron mayores valores con $1.45 \mathrm{~g} . \mathrm{l}^{-1} \mathrm{~h}^{-1}$, esto puede ser debido a la condición del uso de medio sintético como MRS y almidón como suplemento, que aportan suficiente fuente de nitrógeno a las bacterias ácido-lácticas, otro factor a tener en cuenta es que se utilizó otra especie de Latobacillus. Algunos investigadores aseguran que al suplementar con una fuente de nitrógeno se mejora la velocidad de bioconversión (Arrázola Paternina et al., 2013), lo que quedaría por demostrar la factibilidad económica con el uso de suplementos.

El crecimiento de L. casei en el cultivo está directamente relacionado con la concentración de lactosa (Arrázola Paternina et al., 2013), en su estudio obtuvieron un crecimiento de $8.39 \log$ UFC. $\mathrm{ml}^{-1}$ con $87.72 \mathrm{~g} .^{\mathrm{l}^{-1}}$ de lactosa inicial, indicando que bajo esta condición existe una mayor predisposición del medio para el crecimiento del 
Optimización estadística de

microorganismo que para la formación del ácido láctico. Esto podría explicar la razón por la cual los lactosueros con mayor concentración o suplementación de lactosa obtuvieron menor productividad volumétrica de ácido láctico. 


\section{CONCLUSIÓN}

Se logró la optimización de las variables de temepratura y $\mathrm{pH}$ que maximiza la productividad de ácido láctico usando lactosuero a través de el método de superficie de respuesta, siendo una herramienta estadística adecuada para predecir la condición. El lactosuero mostró un gran potencial para ser usado en los procesos de fermentación.

\section{AGRADECIMIENTOS}

Deseamos expresar nuestro agradecimiento a las autoridades de la Universidad Técnica del Norte (UTN, Ibarra, Ecuador) por su apoyo incondicional, y también a Ing. Rosario del Carmen Espín Valladares coordinadora de la Carrera de Agroindustrias por los aportes realizados durante la investigación y en la revisión de este manuscrito.

\section{LISTA DE REFERENCIAS}

Arrázola Paternina, G., García, C., \& Villalba, M. (2013). Producción de ácido lactico de lactosuero suplementado utilizando lactobacillus casei. Biotecnología En El Sector Agropecuario y Agroindustrial, 11(1), (136 - 143).

Chapot-Chartier, M. P., \& Kulakauskas, S. (2014). Cell wall structure and function in lactic acid bacteria. Microbial Cell Factories, 86(6), 4076-4092. https://doi.org/10.1186/1475-2859-13-S1-S9

Dirección General de Salud Pública. (2020). Documento técnico Versión 6: 13 de mayo de 2020. https://www.comunidad.madrid/sites/default/files/doc/sanidad/samb/protocolo_d esinfeccion_de_superficies_y_espacios_habitados.pdf

Eş, I., Mousavi Khaneghah, A., Barba, F. J., Saraiva, J. A., Sant'Ana, A. S., \& Hashemi, S. M. B. (2018). Recent advancements in lactic acid production - a review. In Food Research International, 107(mayo de 2018), 763-770. https://doi.org/10.1016/j.foodres.2018.01.001

Fabro, M. A., Milanesio, H. V., Robert, L. M., Speranza, J. L., Murphy, M., Rodríguez, G., \& Castañeda, R. (2006). Technical Note: Determination of acidity in whole raw milk: Comparison of results obtained by two different analytical methods. Journal of Dairy Science, 89(3), 859-861. https://doi.org/10.3168/jds.S00220302(06)72149-X 
García Gonzalez, E., García Salazar, A. P., Rojas Dorado, M. C., Ordoñez Artunduaga, D. A., \& Serna Cock, L. (2017). Formulación mixta de bacterias lácticas para el control de Listeria monocytogenes. Revista Colombiana de Biotecnología, 19(1), 38-41. https://doi.org/10.15446/rev.colomb.biote.v19n1.55879

Ghaffar, T., Irshad, M., Anwar, Z., Aqil, T., Zulifqar, Z., Tariq, A., Kamran, M., Ehsan, N., \& Mehmood, S. (2014). Recent trends in lactic acid biotechnology: A brief review on production to purification. Journal of Radiation Research and Applied Sciences, 7(2), 222-229. https://doi.org/10.1016/j.jrras.2014.03.002

Gopinath, K. P., Sankaranarayanan, A. R., \& Nivedhitha, L. Platform for chemical biorefinery and agro-industrial waste management. (2016). En Platform Chemical Biorefinery (1. a ed., pp. 379-391). Satinder Kaur Brar, Saurabh Jyoti Sarma, Kannan Pakshirajan. https://doi.org/10.1016/B978-0-12-802980$0.00020-1$

Gorbeña, J. C. R., \& Sáenz, T. A. (2008). Bacterias ácido lácticas. Biotempo, 8, 54-64. https://doi.org/10.31381/biotempo.v8i0.865

Guillamón, J. M., \& Mas, A. (2017). Bacterias del ácido acético. En: König H., Unden G., Fröhlich J. (eds) Biología de microorganismos en uvas, en mosto y en vino. Springer, Berlín, Heidelberg. https://doi.org/10.1007/978-3-319-60021-5_2

Gutiérres Pulido, H., \& De la Vara Salazar, R. (2008). Optimización de procesos con metodología de superficie de respuesta. R. A. del Bosque (2) Análisis y diseño de experimentos, 384-420.

Helmes, R. J. K., López-Contreras, A. M., Benoit, M., Abreu, H., Maguire, J., Moejes, F., \& van den Burg, S. W. K. (2018). Environmental impacts of experimental production of lactic acid for bioplastics from Ulva spp. Sustainability (Switzerland), 10(7), 2462. https://doi.org/10.3390/su10072462

Juodeikiene, G., Vidmantiene, D., Basinskiene, L., Cernauskas, D., Bartkiene, E., \& Cizeikiene, D. (2015). Green metrics for sustainability of biobased lactic acid from starchy biomass vs chemical synthesis. Catalysis Today, 239(1) 11-16. https://doi.org/10.1016/j.cattod.2014.05.039

Kuo, Y. C., Yuan, S. F., Wang, C. A., Huang, Y. J., Guo, G. L., \& Hwang, W. S. (2015). Production of optically pure 1-lactic acid from lignocellulosic 
hydrolysate by using a newly isolated and d-lactate dehydrogenase genedeficient Lactobacillus paracasei strain. Bioresource Technology, 198, 651-657. https://doi.org/10.1016/j.biortech.2015.09.071

Londoño-Hernández, L., Ramírez-Toro, C., Ruiz, H. A., Ascacio-Valdés, J. A., AguilarGonzalez, M. A., Rodríguez-Herrera, R., \& Aguilar, C. N. (2017). Rhizopus oryzae - Ancient microbial resource with importance in modern food industry. In International Journal of Food Microbiology, 257, 110-127. https://doi.org/10.1016/j.ijfoodmicro.2017.06.012

Mirdamadi, S., Atashgahi, S., Rajabi, A., Aziz-Mohseni, F., Roayael, M., \& Hamedi, J. (2008). Cell entrapment of Lactobacillus casei subsp. casei ATCC 39392 for lactic acid production. Iranian Journal of Biotechnology, 6(1), 16-21.

OCE. (2017). The observatory of economic complexity. Where Does El Ecuador Import Ácido Láctico, Sus Sales y Sus Ésteres from? (2017). https://oec.world/es/visualize/tree_map/hs92/import/ecu/show/291811/2017/

Panesar, P. S., Kennedy, J. F., Knill, C. J., \& Kosseva, M. (2010). Production of L(+) Lactic Acid using Lactobacillus casei from Whey. Brazilian Archives of Biology and Technology, 53(1), 219-226. https://doi.org/10.1590/S151689132010000100027

Parra Huertas, S. L., Pérez Casas, M. M., Bernal Morales, M., Suárez Moreno, Z., \& Montoya Castaño, D. (2006). Implementación y evaluación de dos métodos deconservación y generación de la base de datos del banco de cepas y genes del Instituto de Biotecnología de la Universidad Nacional de Colombia (IBUN). Nova, 4(5), 39-48. https://doi.org/10.22490/24629448.346

Reddy, L. V., Kim, Y. M., Yun, J. S., Ryu, H. W., \& Wee, Y. J. (2016). L-Lactic acid production by combined utilization of agricultural bioresources as renewable and economical substrates through batch and repeated-batch fermentation of Enterococcus faecalis RKY1. Bioresource Technology, 209, 187-194. https://doi.org/10.1016/j.biortech.2016.02.115

Sauer, M., Russmayer, H., Grabherr, R., Peterbauer, C. K., \& Marx, H. (2017). The Efficient Clade: Lactic Acid Bacteria for Industrial Chemical Production. In $\begin{array}{llll}\text { Trends in } & \text { Biotechnology, } & \text { 756-769), }\end{array}$ 
Optimización estadística de

https://doi.org/10.1016/j.tibtech.2017.05.002

Singh, S. K., Ahmed, S. U., \& Pandey, A. (2006). Metabolic engineering approaches for lactic acid production. In Process Biochemistry, 3(4). https://doi.org/10.1016/j.procbio.2005.12.004

Taskila, S., \& Ojamo, H. (2013). The Current Status and Future Expectations in Industrial Production of Lactic Acid by Lactic Acid Bacteria. In Lactic Acid Bacteria - $R$ \& D for Food, Health and Livestock Purposes. https://doi.org/10.5772/51282

Teusink, B., \& Molenaar, D. (2017). Systems biology of lactic acid bacteria: For food and thought. In Current Opinion in Systems Biology, 6, 7-13. https://doi.org/10.1016/j.coisb.2017.07.005

Trontel, A., Baršić, V., Slavica, A., Šantek, B., \& Novak, S. (2010). Modelling the effect of different substrates and temperature on the growth and lactic acid production by Lactobacillus amylovorus DSM 20531T in batch process. Food Technology and Biotechnology, 48, 352-361.

Vanegas, M. F., Londoño Z. A., Durango Z. M., Gutiérrez B. M., Ochoa A. S., y Sepúlveda V. J. (2017). Capacidad antimicrobiana de bacterias ácido lácticas autóctonas aisladas de queso doble crema y quesillo colombiano. Biotecnoloía En El Sector Agropecuario y Agroindustrial, 15(1), 45-55. https://doi.org/10.18684/bsaa 